ESJ Social Sciences

\title{
The Typicality of the Agri-Food Product Driver of the Enhancement of Destination Tourism The Apulian Case History
}

\author{
Passaro Pierluigi \\ Arianna Di Vittorio \\ Department of Economics, Management and Business Law, \\ University of Bari "Aldo Moro”, Bari, Italy
}

Doi:10.19044/esj.2022.v18n1p1

Submitted: 08 December 2021

Accepted: 26 January 2022

Published: 31 January 2022
Copyright 2022 Author(s)

Under Creative Commons BY-NC-ND

4.0 OPEN ACCESS

Cite As:

Pierluigi P. \& Di Vittorio A. (2022). The Typicality of the Agri-Food Product Driver of the Enhancement of Destination Tourism. The Apulian Case History. European Scientific Journal, ESJ, 18 (1), 1. https://doi.org/10.19044/esj.2022.v18n1p1

\section{Abstract}

Typical products are becoming more and more an element of differentiation and qualification of entire territories, becoming one of their resources or, in some cases, the main resource and the real tourist attraction factor of the tourist resorts that direct their own promotion strategies of the territory to the new segments of tourist demand (tourists of taste or gastronauts, green tourists). In this sense, it becomes essential to activate synergies and commercial relations with the local economic system (for example with catering, trade, crafts) in order to actively consolidate the ancient territorial link, strengthening its image among consumers: thus, effectively serving as a promotional tool and enjoying the benefits derived from such approaches. Objective of the paper: "Indeterminacy" is the term that characterizes the concept of typicality of the agri-food product and that arises from the low level of information either of consumers and producers of agricultural raw materials and other operators in the supply chain. This work aims to analyze how much the knowledge and impact of the typical Apulian agri-food product affects the choice of the tourist destination. Methodology: The work is based on the analysis of data resulting from a survey in 2020 aimed at potential buyers of the agri-food product aimed at understanding the impact of the typical Apulian agri-food product in the choice of tourist 
destination. Results: The analysis carried out highlighted how the knowledge, awareness and enhancement of typical products represent a strong attractive lever for tourist flows, with a view to choosing the potential final destination. From the testimonies of the users and internal stakeholders it was clear that the typicality has not affected the value of the destination, which remains primary in the purchase intentions of potential customers, but has triggered a climb in the hierarchy of preferences of those who intend to live an experience Italian or foreign tourists, in fact, evaluate the offer enriched by the multiple nuances of the territorial tradition within a specific tourist route. Research limits: This work is intrinsically limited by the strictly qualitative nature of the survey, as well as by the analysis of a single case study. Originality: The originality of the study lies in the contribution it intends to provide to the advancement of research focused on the analysis based on the connection among the territory, typical products and tourist flows.

Keywords: Typical products, valorization, destination tourism, Apulian food

\section{Introduction}

The Italian agri-food industry enjoys an undisputed vocation for quality. This is true not only for the fame of our gastronomic traditions, but also thanks to the value of agricultural raw materials and their great variety, due to a particularly happy and varied intertwining of environmental conditions and historical-cultural sedimentations. Intertwining that runs along the entire peninsula, no area excluded. In particular, the richness and variety of gastronomic traditions in our country undoubtedly represent an important strength in a context of growing appreciation of traditional, diversified products with a strong typical content.

Focusing on quality requires the activation of a series of company functions, aimed at the exact definition of the quality attributes of the product, the identification of the market target, the choice of commercial channels, the relationship with the local culture.

\section{Typical products and their relationship with the territory}

The term "typical" refers to the constant and distinctive characteristics of a certain category of characteristic products originating from a certain geographical area (Nomisma, 2001).

The theme of local development and marketing as a lever to achieve has conquered the world of entrepreneurship in recent decades, with the aim of providing principles, tools and methods to develop the competitiveness of an area through the identification, enhancement and the management of its offer (Sheet, 2001). In this sense, territorial marketing is a complex and integrated set of resources, economic subjects, social and cultural factors; as a 
"system" capable of creating and sustaining demand and orienting the offer of services and products to market needs (Paolini, 2000); it also proposes to provide a correct approach for the inclusion of the heritage of typicality in particular of food and wine and culture, which are increasingly important for the success of the tourist offer programs of an area, guaranteeing differentiating characters and visibility (Nomisma, Palomba, 2009).

If on the one hand, therefore, territorial marketing sees in the food and wine culture the tool of choice for realizing itself, on the other the psychology of consumption and its related effects opens an interesting chapter on consumption choices, on shopping experiences, and on determination of tourist destinations (Pencarelli, 2012). Many consumers associate the concept of typicality exclusively with certain characteristics or values of the product, not considering how this term goes beyond the simple quality or genuineness of the same. (Croce, Perri, 2010).

Producers, on the other hand, very often fail to grasp the real potential of this "label" in the enhancement and territorial development and, above all, how this meaning can be translated into marketing and business development strategies (Nomisma, 2001). It is for these reasons that it is necessary to clarify the real meaning of the term "typicality" in the world of agri-food, a term that is now inflated, abused and caused by a distortion of its deeper meaning.

Interesting is the scope and relevance that territorial marketing has acquired over the last few decades through the enhancement of the food and wine culture, which has now become an essential tool for the development, launch and/or increase of the activities of a "place" (Curini, 2014). Typicality as a factor to be enhanced and preserved to strengthen, specialize, diversify and create products and supply networks in the area, to link tourist productivity to agricultural and agri-food productivity, to give "industrial" strength to minor productions, which risk being lost. Furthermore, another objective is to identify how the new consumption, or, better said, the new ways of using products, can be transformed into the main factors of competitive advantage and a vehicle for development for the territory (Crouch, Ritchie, 2003).

With reference to the "typical product" (Belletti, Brunori, 2006), it is "a product that has some unique quality attributes, which are an expression of the specificities of a particular territorial context in which the production process takes place" .

"Specificity" means the set of elements that distinguishes an agri-food product from other similar ones belonging to the same category. The territory represents an important element in the specificity for the specific exogenous factors of the production area, of the processing area and of the prevailing marketing area: climate, land conformation, historical and cultural heritage favor unique and consolidated processes over time (Marescotti, 2006). 
The aforementioned definition of product, however, does not fully highlight the value of the human factor, aggregator of knowledge, know-how and local practices, fundamental for obtaining the typical product, and of the emotional, social, epistemic and contextual factors that they allow the consumer to "benefit not only from qualitative excellence but above all from geographical and cultural links through which to acquire the possibility of accessing a specific social and cultural context" (Cesaretti, Annunziata, 2011).

These factors, relevant in determining the typicality of the product, can be gathered around three axes (Mipaaf degree n. 350/99):

- the specificity of the local resources used in the production process;

- the history and production tradition;

- the collective dimension and the presence of shared knowledge at the local level.

The existence of a close relationship between the typical product and a certain territorial area represents the so-called geographical dimension, a set of geographical and climatic conditions that give the product its own specificity (Angeloni, 2013). Geographical location stands as a requirement of fundamental importance since the qualitative image of the typical product must be immediately connected and identifiable with the territory of origin. For a consumer, in fact, the territorial origin of a typical product represents a fundamental element in terms of differentiation, as it is increasingly perceived as an element of reassurance.

The historical dimension, on the other hand, refers to the knowledge, traditions, uses, culture connected to the product and the set of know-how that have consolidated over time by taking root and implying its ancient presence in the territory. Together with the aforementioned geographical location, the historical memory is perhaps one of the most important and characterizing elements of the typical product. Lastly, the so-called cultural dimension indicates the way of living and thinking of the people who live in the product production area (Presenza, 2007).

These dimensions tend to overlap, so as to attribute the requirement of typicality to the product. There are three different degrees:

- the first level consists of products for which production and consumption were originally carried out in a rather large area and that is why they could be made in another territory without generating confusion in the consumer, since the product-territory link is only an image link with the place;

- the second level consists of products obtained with raw materials present in the place of origin of the product. These are related to the concept of "quality"; they are in fact defined as "quality raw materials" and derive from a long tradition handed down for years and have 
undisputed organoleptic properties. These goods could be made elsewhere, but the typicality derives from the raw materials used for their production, from the transformation process and from the marketing methods.

- The third and last level considers those products that use production methods developed in the geographical area of origin and which cannot be replicated elsewhere. This gives the product unique connotations and its degree of typicality is greater than the products of the first and second level.

Other discriminants should be considered to define a product as typical:

- Intertemporal space: time that has elapsed since the first marketing, that is, a product must have been known for at least thirty years.

- Preparation techniques: a product must follow preparation techniques consolidated over time and adequately handed down.

- Product characteristics: requirement that includes all the organoleptic and nutritional characteristics of the product.

Others connected elements: all those elements which, although not directly connected to the product, play a very important role, such as the quantity produced, the type of distribution and storage, the mode of consumption, the sales area (Bottinelli, 2004).

In relation to the requirements described above, three major macrocategories of typical products can be highlighted:

- certified typical products: with quality certificates (such as DOP and IGP) and characterized by a restricted production and marketing area;

- typical non-certified products: of high quality and tradition, they do not have a recognition mark. They are characterized by a notable commercialization even outside the local borders, which determines a strong potential in terms of expansion of their market;

- high-consumption undifferentiated products: well known and with a high level of standardization, characterized by an industrial production process and delocalized marketing.

The typical product must not be confused with the "local product", which expresses, instead, the physical proximity between a product and a consumer. In the case of the typical product, reference is made only to the geographical origin. The local product, therefore, does not have that "close traditional and cultural link that allows it to be typical and therefore differentiate it from other similar products" (Caroli, 2011). 
The term "traditional product", on the other hand, is the result of a historical production tradition that has not wanted or been able to adapt to modern and standardized techniques. A typical example is the PAT (Traditional Agri-food Products), included in a special ministerial list, with the task of promoting their knowledge at national and international level.

A final differentiation is that which concerns "Made in Italy" products compared to typical ones. The "Made in Italy" products, in fact, take into consideration the entire national geographical area and are made with a production process that can be replicated even outside national borders (Spendiani, 2017).

\section{Typicality as an element of differentiation}

Typical products lend themselves to effective product differentiation, leveraging some peculiar characteristics, for example:

- the location of the product and the production techniques used for its realization within the local tradition and culture;

- the geographical location of the production area;

- the quality of the raw material used and the peculiarities of the production processes deriving from a certain local production tradition.

The link of the typical product with the territory also refers to the aspects of culture and local identity. Very often the typical product characterizes the "historical memory" of the local population, not only in terms of production, but also in terms of its use in gastronomic preparations and social consumption practices, thus representing an element of identity. The cultural and identity element takes on a very important catalyst value of the local community's desire to preserve the product and can strengthen the enhancement processes that are activated locally (Bérard, Marchenay and Casabianca, 2005).

The reference to the link with time and memory, with local traditions and culture, requires us to consider the theme of innovation, a central aspect as often the enhancement of the typical product requires modifying consolidated traditions with respect to the production process and, sometimes, with respect to the product (Marescotti, 2006). The link between product and territory cannot be considered as a rule written once and for all (today many typical products, if made with the techniques and in the manner of a hundred years ago, would not even be considered edible by consumers), but it must be continuously reinterpreted in the light of changes in the local and global context.

The third set of factors relevant to typicality can be identified in the collective dimension (Belletti, 2002; Belletti, Brunori, Marescotti and Rossi, 
2002), intimately linked to history and traditions. The typical product, unlike other products of specific quality (such as a product from organic farming), is closely linked not to a single individual or company but to a community of actors, by virtue of the link with a given territory that is it is established, refined, consolidated and modified over time. The typical product is the result of an interaction between the different local producers, and between them and the local population, as well as, when the system opens to more distant markets, with consumers and non-local citizens; it incorporates knowledge built over time and shared within a territorialized community. This process of accumulation and sedimentation of knowledge (contextual and often not codified) means that we can talk about the patrimonial dimension of the typical product (Bérard and Marchenay, 2006), the product, and the ways to produce it, preserve it, distribute it, consume it and appreciate it. they become part of the heritage of the local community. It alone is therefore entitled to appropriate it for economic, social and cultural purposes. Therefore, typicality is not built only on the characteristics of the production process and of the product, but also (and, perhaps, above all) on the relationships between the actors of the system.

Differentiating a product depends not only on the product itself, but on the company's ability and ability to develop and communicate properly with a brand and any other distinctive elements that can be recognized as such by consumers. In particular, considering the entire production chain of an agrifood product, it is clear that "the possibility of differentiating is considerably reduced at the farm level, while it increases in the more downstream phases of the supply chain, when it comes to industrial transformation or marketing" (Antonelli, 2011).

In this panorama are placed the products with the marks of designation of origin, established by the European Union, for which, also on the basis of the institutional regulations (EC Regulation 510/2006), increasing levels of typicality are recognized respectively for STG, PGI and DOP. To these categories are added the products awaiting the completion of the registration procedure for the PDO or PGI denomination and those that for various reasons are proposed to the consumer as typical, such as traditional, farm, local, park / protected area products.

Typicality therefore represents a condition for the differentiation of agri-food goods; a condition that exists exclusively in the potential state and that can be transformed into effective differentiation only through appropriate and effective marketing policies, of which the consumer is able to perceive the value (Martini, 2005).

In essence, marketing has the function of transmitting the signals of value which, if recognized and perceived favorably by the consumer, lead to the formation of a Premium Price. In this perspective, the problem of product 
differentiation, even in the consumer's mind, essentially requires marketing policies to be implemented to remove situations of information asymmetry. This occurs on the markets of agri-food products due to the great variety of products that are apparently similar in that they belong to the same product category and the difficulty for the consumer to correctly evaluate the qualitative differences. This happens due to a multiplicity of requirements of the product-producer system not directly ascertainable and assessable by the consumer (nutritional and health requirements, the effectiveness of process control systems, origin, hygienic compliance, application of specific technologies, etc.) that incentivize large retailers to adopt aggressive pricing strategies, relying on vast economies of scale, reputation and customer loyalty. This process leads to a reduction in the supply of products with non-definable technologies, leading, in the longer term, to their disappearance on the market to the advantage of those of standard quality.

The consumer, even if interested in buying a different product, will be oriented to face a higher outlay only if he is able to perceive the qualitative difference, otherwise, his rational behavior will lead him to buy the product that has a lower price. Therefore, for the producer of the highest quality agri-food product the problem is to be able to "communicate" to the consumer the qualitative characteristics (organoleptic, nutritional and intangible) that differentiate his product from the standard one (Prestamburgo, Torquati, 2004). Basically, it is a question of implementing a strategy that allows to differentiate the product not only substantially, but also and above all in the perception of the consumer.

\section{3. $\quad$ Methodology}

This work was based on the analysis of data deriving from a survey in 2020, carried out on 200 people (ages 18 and up), aimed at potential buyers of the agri-food product aimed at understanding the incidence of the typical Apulian agri-food product in the choice of tourist destination.

The questionnaire on the appeal, knowledge and impact of the typical Apulian agri-food product in the choice of tourist destination, was created and submitted to potential buyers of the typical agri-food product. The information obtained was suitably analyzed and transcribed into graphs and tables, according to a descriptive statistical methods, with both quantitative and qualitative variables. A further exploratory analysis, which relates the data to each other, can be a subsequent level of the research.

This made it possible to observe both the incidence of the typical product in the choice of the tourist destination, and the knowledge of the characteristics that make it a certified product. In particular, the questions were formulated with the aim of obtaining information of a predominantly quantitative nature and were set according to a multiple choice or hierarchical 
scheme, allowing the interviewee to choose the most suitable answer to his opinion. The questionnaire, divided into twenty-two questions (excluding those relating to identity and profession), was preceded by a letter of presentation in which the title of the research and a brief description of its objectives were reported, highlighting the importance of obtaining the information requested for the purposes of research and processing of the collected data.

\section{Presentation and discussion of the results}

Respondents constitute a balanced segment of potential buyers of the product; segment varied by age, level of education and profession.

Graph 1: socio-demographic segmentation (age, level of education, profession)

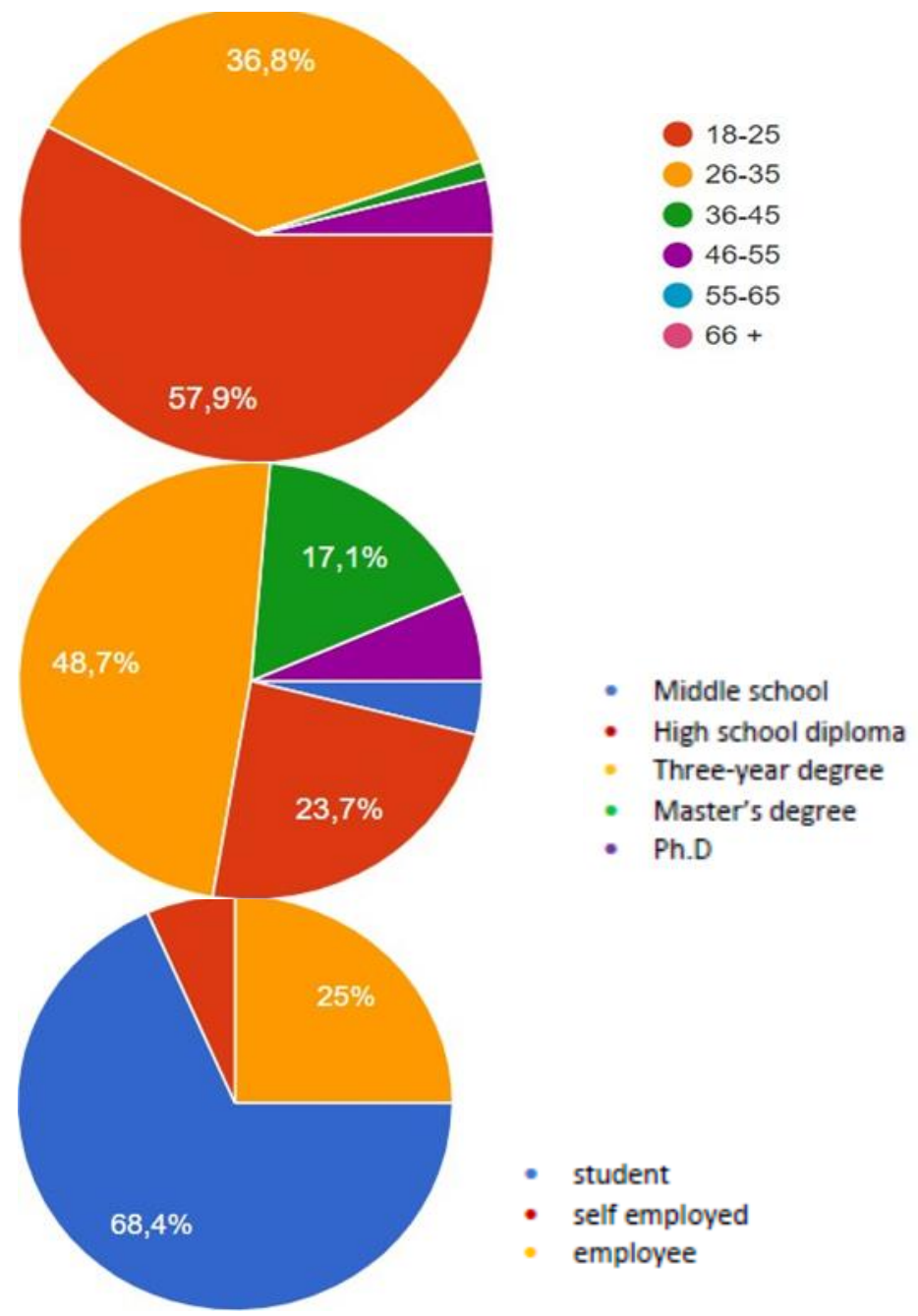

Source: 2020 survey data 
These were initially asked how often they traveled during the year, with reference to the pre-pandemic period. $43.4 \%$ replied "once", $47.4 \%$ said they travel "twice during the year", while the remainder expressed the habit of traveling more frequently. At this point we wanted to understand what rate of incidence the typical agri-food offer has on the choice of the tourist destination, and the relevant data was, certainly, that for which none of these potential travelers opts for a specific territory as a result of a 'territorial agrifood offer; and indeed, $42.2 \%$ give little importance to the element when selecting the destination.

Graph 2: Impact of the agri-food factor on the choice of a destination

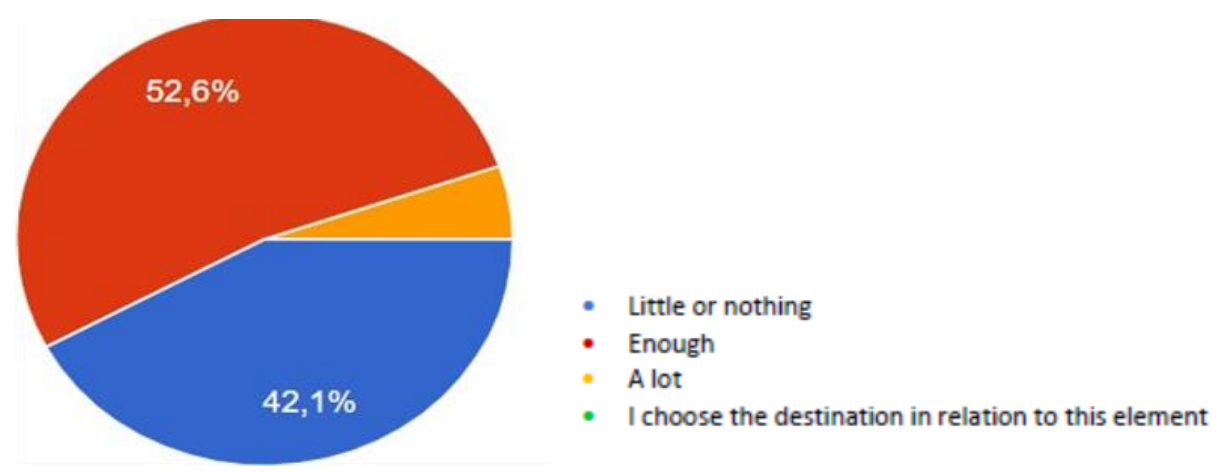

Source: 2020 survey data

Having understood the general picture, we wanted to enter the field of specific preferences, needs and purchasing habits of potential customers, focusing on the choice of agri-food product, free from the concept of destination, by the interviewees:

Graph 3: Factors for choosing the agri-food product

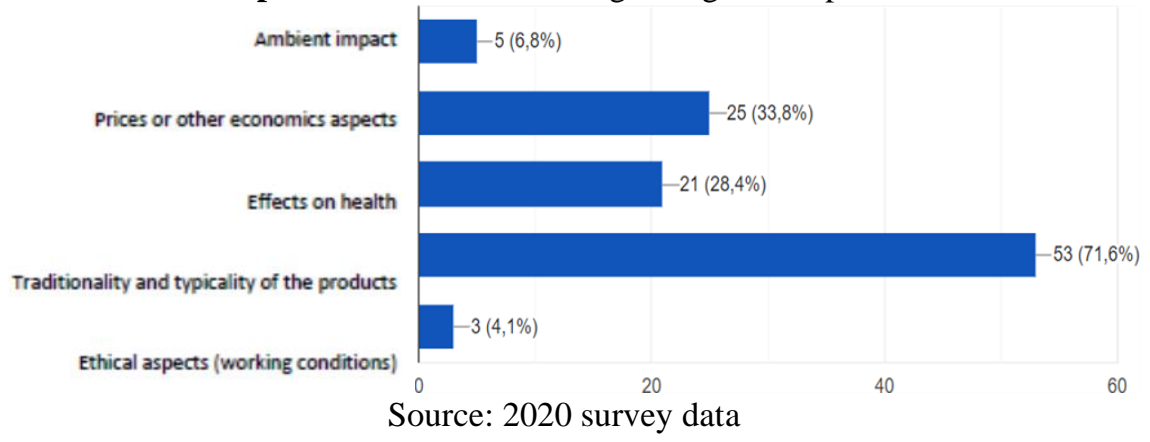

And $85.5 \%$ also stated that when choosing the typical agri-food product, the label plays a fundamental role for the following reasons: 


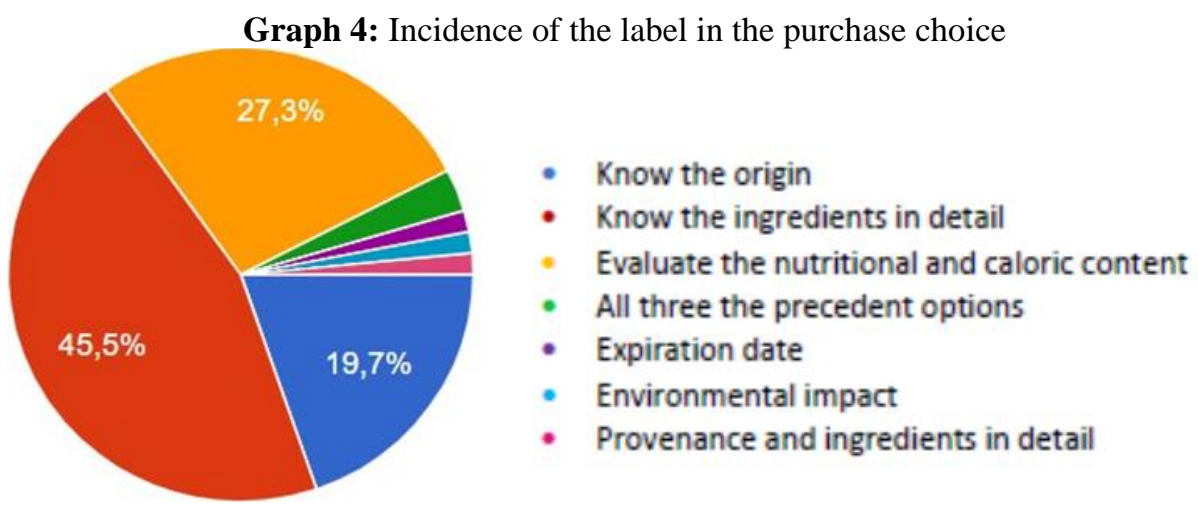

Source: 2020 survey data

The data collected show that $59.2 \%$ of the interviewees are (paradoxically) more incentivized to purchase agri-food products, if the process underlying their production safeguards the cultural heritage.

Graph 5: Elements that affect the purchase choice

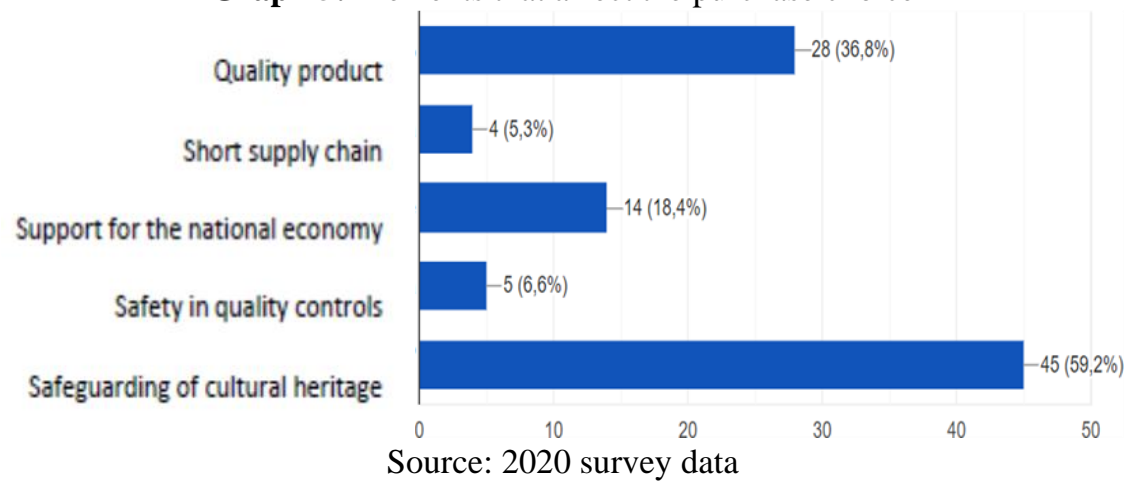

Speaking of the Puglia region, $100 \%$ of potential buyers confirmed that they usually know and consume traditional products (total percentage due to the geographical origin of the interviewees, all native to the region). Going into detail, $55.8 \%$ consumes them two or more times a week and $14.3 \%$ even every day.

Graph 6: Purchase motivation

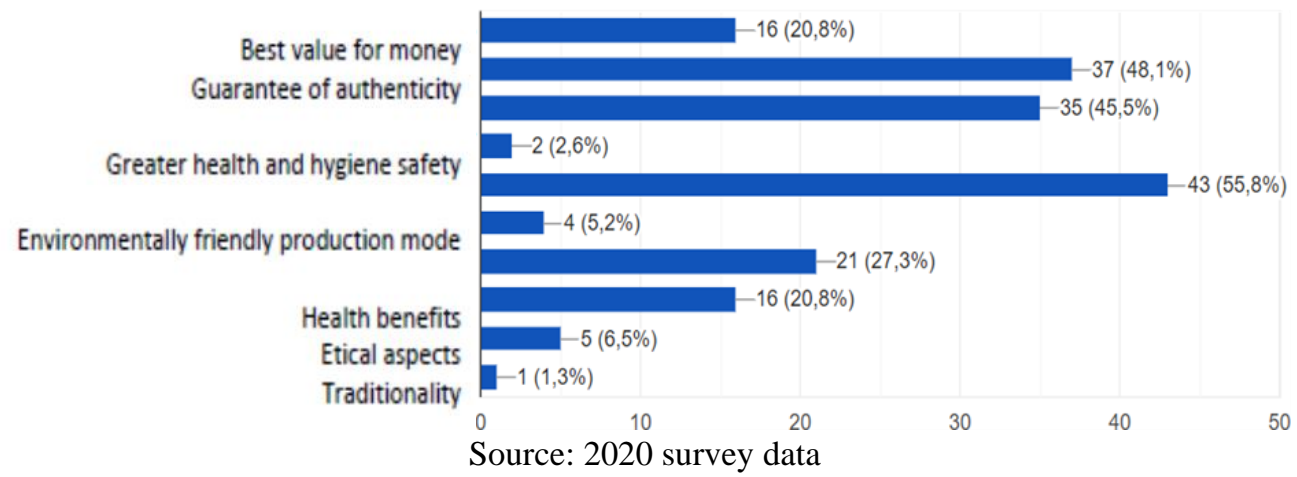


The aforementioned question was followed by an open question, the subject of which concerned which product best represented the Apulian identity; the plebiscite response was the combination: Orecchiette and extra virgin olive oil. A concept that cannot be overlooked, speaking of the propensity to purchase a typical agri-food product, is that of the willingness to pay a premium for this product; surcharge that refers to the concept of typicality of the agri-food product.

Graph 7: Willingness to pay a premium

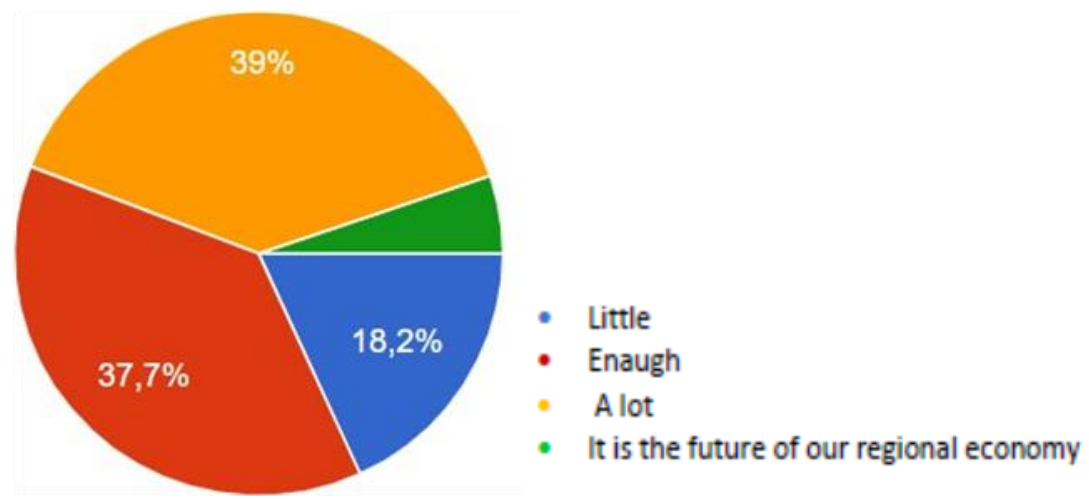

Source: 2020 survey data

Turning to the topic of quality certifications (DOC, IGP, DOCG and DOP), 79.2\% replied that they know these brands, but not to the point of considering them primary elements in the evaluation of the purchase of the products in question:

Chart 8: Impact of quality certifications in purchasing choice

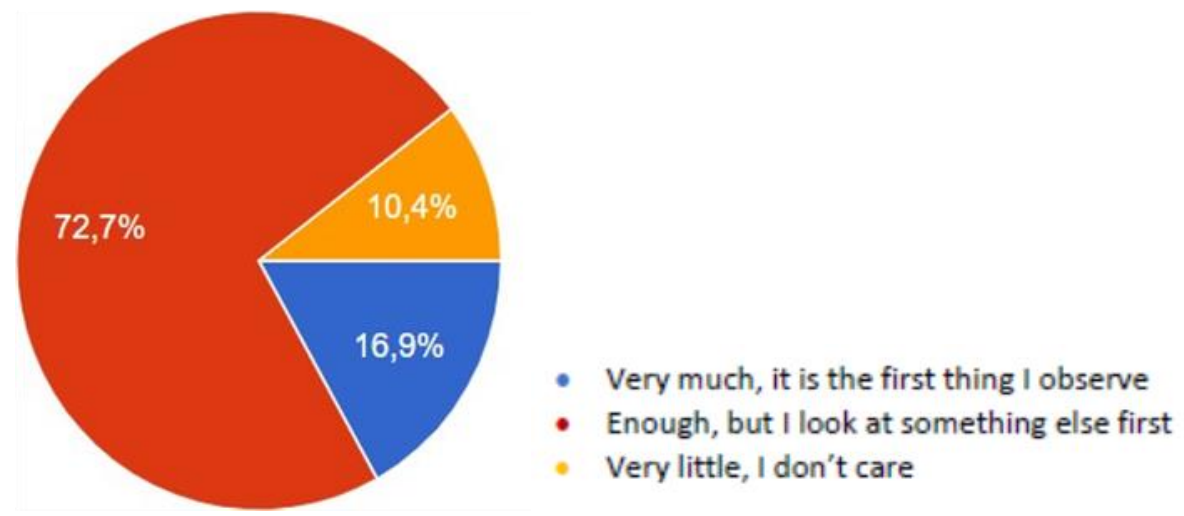

Source: 2020 survey data

Finally, returning to the relationship between typical locality and choice of destination, the respondents to the questionnaire indicated for $62.3 \%$ "cultural experience" as an answer to the question on how the tourist consumption of local production can be interpreted. On the other hand, the 
response on how much further investments on "agri-food itineraries in Puglia" may affect the tourist development of the territory has been balanced. In fact, although the majority, only $37.7 \%$ of those interviewed believe it constitutes the future of the economy of this region.

Graph 9: Impact of food and wine on future prospects

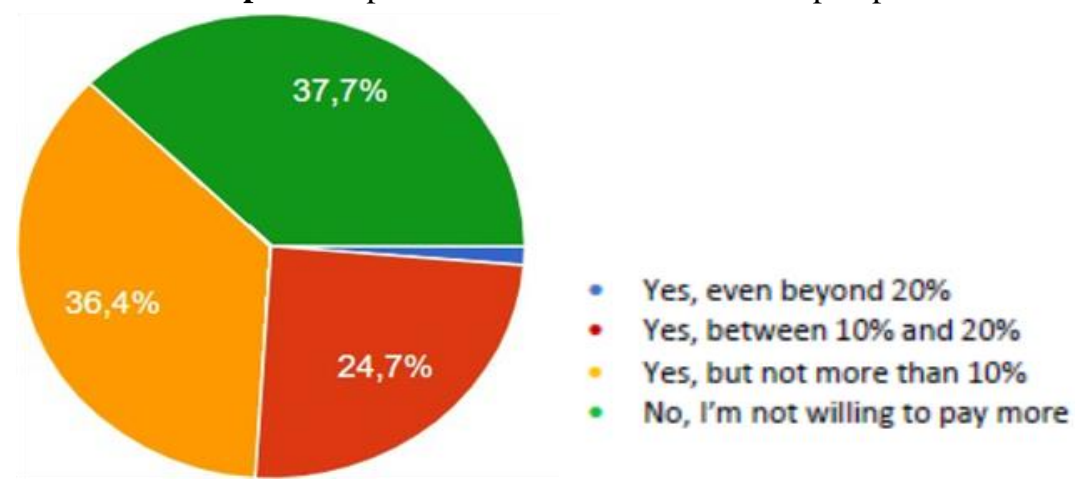

Source: 2020 survey data

Ultimately, returning to what was stated in the 2nd paragraph, the existence of a close relationship between the typical product and a certain territorial area represents a strong geographical dimension, a set of geographical and climatic conditions that give the product its own specificity (Angeloni, 2013). So geographical location stands as a requirement of fundamental importance since the qualitative image of the typical product must be fastly connected with the territory of origin. For a consumer, in fact, the territorial origin of a typical product represents a great and real element of differentiation, as it is increasingly perceived as an element of reassurance.

Besides, about historical dimension refers to the knowledge, traditions, uses, culture connected to the product and the set of know-how that have consolidated over time by taking root and implying its ancient presence in the territory. Together with the geographical location, the historical memory is a very important and characterizing element of the typical product. So, the cultural dimension shows a better way of living and thinking of the people who live in the product production area (Presenza, 2007).

\section{Conclusion}

Wanting to make a "balance" about the role assumed by typical products, it can be considered as a whole that these constitute a key element in the enhancement of the territory, especially with reference to the agri-food sector. From the testimonies of the users and internal stakeholders it was clear that the typicality has not affected the value of the destination, which remains primary in the purchase intentions of potential customers, but has triggered a climb in the hierarchy of preferences of those who intend to live an experience 
Italian or foreign tourists, in fact, evaluate the offer enriched by the multiple nuances of the territorial tradition within a specific tourist route (from the location to the table, up to the experiences outside); this as a result of the growing attention of consumers to the quality and authenticity of the experience.

The typicality, in addition to constituting a positive differential for the tourist and a surplus value for already attractive territories, represents a potentially relevant resource also for agricultural enterprises located in territories considered marginal and economically more disadvantaged in order to obtain a space for competitiveness in a market. increasingly competitive (Sainaghi, 2008). The recognition of the Italian agri-food sector as having a central role in the development of territorial systems is now unanimous. This development allows the achievement of specific economic and social benefits. Just think that:

- the agri-food system generates a total of over 250 billion euros per year in turnover;

- considering the induced generated, it comes to represent more than $15 \%$ of the Italian GDP;

- Made in Italy agri-food products reached an average growth rate of around $10 \%$ from 2008 to 2020 ;

- there is both a growth trend in employment in the sector and an increase in the demand for food and wine tourism.

However, the obstacles and problems about destinations valorization that may arise can be of different nature, and may concern:

- little information on the intrinsic value of the product in reference to the commitment necessary for the realization, to the value of the raw material used to the value of precious and irrecoverable testimony of a specific rural environment;

- insufficient remuneration for the producer who has failed, or is unable, to distinguish his production from similar mass products obtained at significantly lower costs;

- absence of a collective image and general legislation that distinguishes the entire category of typical -local products from the numerous imitations present on the market;

- marketing carried out largely in an elementary and approximate way;

- difficulty in planning promotional interventions aimed at the single product due to the high costs.

In the face of these problems, positive signs emerge, which lead us to look with confidence at the commercial future of local products: 
- a generalized increase in consumer interest in what has been defined as the "food satisfaction" area;

- the greater sensitivity to give the right weight to health reasons (genuineness, absence of additives, use of valuable raw materials) in the choice of products;

- the development of the agritourism phenomenon which acts as a promotional factor for typical local products;

- a certain interest on the part of the legislative and government bodies in typical and local products;

- the realization of numerous studies, research aimed at the census and the dissemination of many products otherwise destined to fall into oblivion.

The possibility of the primary sector to develop through typical agrofood productions also depends on the ability of this offer to meet certain segments of demand.

If this were not the case, this would mean relegating the typification paths to a large exhibition of works of art that would not however have admirers and visitors.

Focusing on the case of Puglia, the presence of a not indifferent typical heritage on which the offer system rests was demonstrated, which satisfies the different needs of both residents and tourists. It was possible to ascertain, from interviews with privileged witnesses, the importance of a $0 \mathrm{~km}$ production for the territory and its combination, in the offer, with the destination and the cultural aspect. In the last three years, prior to the pandemic, the first accounted for the largest percentage of turnover for companies that diversify their business between hospitality and production, with prices doubled.

All with a promotional push not deriving from the institutions but the consequence of a social trend that has allowed the phenomenon to emerge. Therefore, greater public intervention would be necessary to promote above all those productions that, in addition to not having a consistent market, are unknown to the most unknown. some actions can assume a significant strategic role (Della Corte 2012):

- select all the structures that guarantee the relationship between typicality and quality, from all company points of view;

- start a training activity aimed at professionals who do not yet possess the required quality requirements;

- identify a list of targeted events, to be included in tourist packages to complete the offer of quality accommodation facilities, together with the generic cultural offer; 
- build some packages to be submitted to tour operators specialized in food and wine tourism, possibly involving tourist associations, which need to be revitalized;

- organize special educational for the specialized press;

- create a dedicated website / portal;

- through local authorities and actors, prepare regional sector legislation which, in particular, governs the certification of hospitality;

- publish calls for training; support, also involving private individuals, the costs and expenses of communication and promotion.

In an attempt to outline the salient features of local food and wine and its tourist connotations, the ideal route winds through typical territorial initiatives and events, overlaid by the enormous heritage deriving from Apulian gastronomy and tastes. In fact, it is not possible to ask individual entrepreneurs / producers, especially following a period of crisis such as the one we are experiencing, to bear huge economic expenses in order to implement specific marketing and communication policies. In any case, it is considered appropriate to protect and preserve these productions, because in the near future they could take on a certain depth for the enhancement of the territory (Desinano, 2019).

Indeed, it would be a huge mistake to lose the history, culture and tradition that embodies a local product. The Italian agri-food industry plays a primary role and, to date, can be considered a driving and growth sector (Tamma, 2009). Typical production, in fact, constitutes an important opportunity for economic development for the area, as well as for the agrifood system itself.

The demand from local and foreign consumers for typical quality products is constantly increasing and this is a positive factor useful both in solving problems of insufficient competitiveness and in strengthening the image of individual territories. Finally, it is important to remember that the success of a typical product depends on the link with the territory to which it belongs. We must therefore reflect the image of naturalness, safety and genuineness that increasingly conditions those consumers with a certain food culture.

\section{References:}

1. Angeloni, S. (2013). Destination Italy: Un approccio manageriale per il sistema turistico italiano. Milano: Pearson.

2. Antonelli, G. (2011). Marketing dei prodotti agroalimentari tipici e di qualità, Università degli studi di Urbino "Carlo Bo".

3. Belletti G. (2002). Sviluppo rurale e prodotti tipici: reputazioni collettive, coordinamento e istituzionalizzazione, in: Basile E., 
Romano D. (a cura di), Sviluppo rurale: società, territorio, impresa. Milano: Franco Angeli.

4. Belletti G., Brunori G., Marescotti A., Pacciani A., Rossi A., Rovai M., Scaramuzzi S., (2006). Guida per la valorizzazione dei prodotti agroalimentari tipici. Concetti, metodi, strumenti. Firenze: Arsia.

5. Bérard L., Marchenay P. (2006). Local products and geographical indications: taking account of local knowledge and biodiversity, International Social Science Journal, 187, pp. 109-116.

6. Bottinelli L. (2004). La nascita e lo sviluppo del marketing relazionale. Quaderno di ricerca n. 5. Università degli studi di Pavia.

7. Caroli M. G. (2011). La competizione tra territori, in Caroli M. G., Il marketing territoriale: idee ed esperienze nelle regioni italiane. Milano: Franco Angeli.

8. Casabianca F. (2003). Les produits d'origine: une aide au développement local, in Delannoy P., Hervieu B. (a cura di), A table. Peut-on encore bien manger?. Paris: Editions de l'Aube.

9. Cesaretti G. P., Annunziata A., (2011). Strategie e strumenti per la valorizzazione sostenibile delle produzioni agroalimentari di qualità. Milano: Franco Angeli.

10. Cicia, G., Cembalo, L., Del Giudice, T., Verneau, F. (2013). Il sistema agroalimentare e il consumatore postmoderno: nuove sfide per la ricerca del mercato, Rivista Economica Agroalimentare, 54.

11. Cinti, D. (2014), Turismo rurale e progetto di paesaggio. La Valtiberina toscana per un turismo culturale e naturale sostenibile. Milano: IBS.

12. Cresta, A., Greco, I. (2011), Luoghi e forme del turismo rurale. Evidenze empiriche in Irpinia. Milano: Franco Angeli.

13. Croce E., Perri G. (2010). Il turismo enogastronomico. Progettare, gestire, vivere l'integrazione tra cibo viaggio, territorio. Milano: Franco Angeli.

14. Crouch G.I., Ritchie J.R.B.(2003). The competitive destination. A sustainable tourism perspective, CAB Publishing.

15. Curini, G. (2014). Franchising turistico come supporto al Destination Management.

16. Della Corte V. (2000). La gestione dei sistemi locali di offerta turistica. Padova: Cedam.

17. Della Corte V. (2012). Destination Management e logica sistemica: un confronto internazionale. Torino: Giappichelli.

18. Desinano, P. (2019). Destination management: prospettive teoriche e modelli applicativi. Destination management, 1-143.

19. Foglio A., (2001). Il marketing agroalimentare: mercato e strategie di commercializzazione. Milano: Franco Angeli. 
20. Keller, K. L. (2013). Conceptualizing, Measuring, and Managing Customer-Based Brand Equity. Journal of Marketing, 57(1), 1-22.

21. Keller, K. L., Busacca, B., Ostillio, M.C. (2014), Gestione e sviluppo del brand. Milano: Egea. Ed.or.: Strategic Brand Management (Keller, K. L., 2003).

22. Kotler P., Scott W.G., (1993), Marketing Management: analisi, pianificazione, attuazione e controllo. Torino: ISEDI.

23. Kotollaku M.,Margariti M. (2015). Cultural tourism in Gijrokastra. European Scientific Journal, Vol.11, No.14.

24. Lo Surdo, G. (2013). Il marketing delle nuove vacanze. Comunicazione e mezzi di promozione del turismo rurale, enogastronomico, della natura, del wellness. Milano: IBS.

25. Marescotti A. (2006). Le dimensioni della tipicità dei prodotti agroalimentari, in Arsia, Guida per la valorizzazione dei prodotti agroalimentari tipici. Concetti, metodi e strumenti. Firenze: Arsia.

26. Martini U. (2005). Management dei sistemi territoriali. Gestione e marketing delle destinazioni turistiche. Torino: Giappichelli.

27. Nomisma (2001). Prodotti tipici e sviluppo locale: il ruolo delle produzioni di qualità nel futuro dell'agricoltura italiana, $8^{\circ}$ rapporto Nomisma sull'agricoltura italiana. Milano: Il Sole 24 Ore.

28. Nomisma, Palomba P. a cura di (2009). Marketing dei prodotti tipici. La valorizzazione dei prodotti agroalimentari "del territorio": criticità, prospettive e rapporti con la Grande Distribuzione". Roma: Agra Editrice.

29. Ozyer Y. (2016). Relationshıp Among Humor Styles, Internal Marketıng Practices And Communication. European Scientific Journal, Vol.12, No.4.

30. Paolini D. (2000). I luoghi del gusto. Cibo e territorio come risorsa di marketing. Milano: Baldini \& Castaldi.

31. Pencarelli, T. (2012). Il Destination branding nel governo strategico delle destinazioni turistiche.

32. Pine, B.J., Gilmore, J.H (2000). The experience economy. Work is theatre \& Every Business is a stage. Boston: Harvard Business School Press.

33. Presenza A. (2007). Destination Management Organization. Milano: Franco Angeli.

34. Prestamburgo S., Torquati B. (2004). Ricerca delle origini teoriche del marketing agroalimentare, in Antonelli G. a cura di Marketing Agroalimentare. Specificità e temi di analisi. Milano: Franco Angeli.

35. Resciniti R. (2014). Il marketing orientato all'esperienza. L'intrattenimento nella relazione con il consumatore. Milano: Edizioni 
Scientifiche Italiane.

36. Rocchi B, Romano D. (2006). Tipicamente buono. Concezioni di qualità lungo la filiera dei prodotti agro-alimentari in Toscana. Milano: Franco Angeli.

37. Rossi, A., Goetz, M. (2014). Creare offerte turistiche vincenti con Tourist Experience Design. Milano: Hoepli.

38. Saija R., Philipp F. (2020). La qualità e le qualità dei prodotti alimentari, tra regole e mercato. Padova: Cedam.

39. Sainaghi, R. (2008). Attrattori e prodotti turistici: il binomio della competitività. Attrattori e prodotti turistici 1000-1023.

40. Splendiani S. (2017). Destination management e pianificazione turistica territoriale, 1-138.

41. Tamma M. (2009). Destination Management. Milano: Touring University Press.

42. Ukai F. (2015). Internet marketing and on line consumer behavior in the case of Kosovo Market. European Scientific Journal, Vol.11, No.25.

43. Yu C.E., Zhang X. (2020). I sentimenti incorporati nella gastronomia locale: un'analisi del sentimento delle recensioni online. Giornale di tecnologia dell'ospitalità e del turismo, September 2020. 